\section{A first in computer printing}

London

A working model of what is claimed to be the world's first computer printer was unveiled at the Science Museum in London last week. The printer was designed - but never built - by Charles Babbage (1791-1871), the inventor and mathematician widely acknowledged as the 'father of computing'.

In 1821, Babbage was checking mathematical tables that had been calculated by hand. Finding error after error, he exclaimed: "I wish to God these calculations had been executed by steam." He designed a calculating machine and a printer, but only built a small part of the calculating machine.

The machine was completed in 1991 by the museum's Babbage Project, using Babbage's original designs. The project has now completed the printer. Natasha Loder

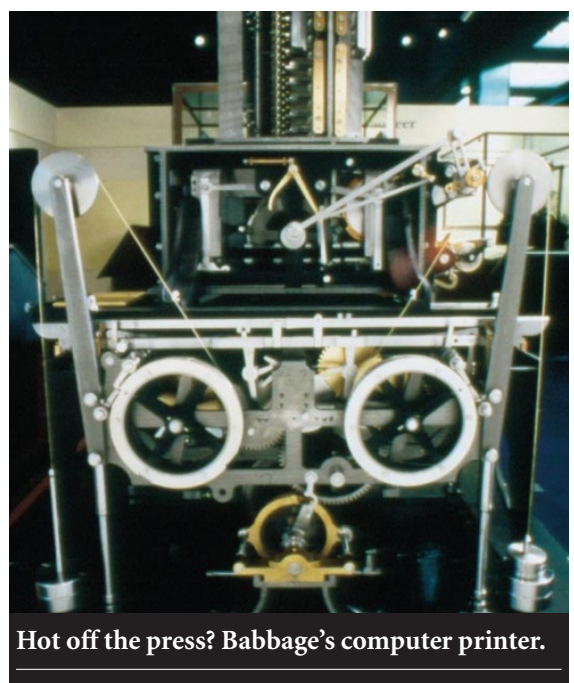

\section{US energy agency sequences human chromosome trio}

Washington

The publicly funded Human Genome Project received a boost last week with the announcement that 'working drafts' of the sequences of three human chromosomes have been assembled. The chromosomes numbers 5, 16 and 19 - have been sequenced by scientists at the US Department of Energy's (DoE's) Joint Genome Institute (JGI) in Walnut Creek, California.

The revelation followed a recent statement from Celera Genomics that it had completed the raw sequencing phase of its private human genome project (see Nature 404, 691-692; 2000). But Ari Patrinos, leader of the DoE's sequencing effort, denies that the announcement was prompted by Celera's latest claim. "We didn't make our announcement because of the Celera announcement," Patrinos told Nature.

Celera had earlier declared it would assemble its raw data into a draft genome within six weeks. The DoE's announcement effectively allows the agency to claim a measure of success before that date.

Francis Collins, the head of the Human Genome Project, says that the DoE "deserves a lot of credit for getting their three chromosomes up to working-draft status early". He adds that the rest of the genome "isn't far behind". A meeting of the main five sequencing centres - of which JGI is one - in Houston last week confirmed that "things are in excellent shape", he said.

The JGI has 'read' at least 90 per cent of the DNA in the three chromosomes at least five times. This ' $5 \mathrm{X}$ coverage' increases the draft sequence's level of accuracy, although it still leaves gaps in each chromosome. Chromosomes 5 and 16 have been sequenced to about $5.4 \mathrm{X}$ coverage, while chromosome 19 has been sequenced to nearly $9 \mathrm{X}$ coverage. The international genomics community generally considers $10 \mathrm{X}$ to be the gold standard for a fully sequenced genome.

The draft sequences mark a turning point for the DoE's role in the international Human Genome Project. The JGI will finish the three chromosomes and may then head in a different direction.

The DoE's approach to the collaborative project has been different from those of other players. Unlike chromosome 22, for example, which was sequenced through the joint efforts of several laboratories around the world, JGI scientists sequenced all three of their assigned chromosomes in one facility.

Once the Human Genome Project achieves 5X coverage of 90 per cent of the human genome, some of the high throughput capacity in the United States will switch to sequencing the complete mouse genome. In contrast, the JGI will only sequence the portions of mouse chromosomes that are homologous to the three human chromosomes that it has sequenced.

The JGI will also shift the emphasis of its sequencing efforts to the genome of another organism, which the institute is likely to complete itself. The institute's advisory board will meet later this month to begin determining which organism it will tackle. Paul Smaglik
Bid to relax rules on tissue transport runs into opposition

Cape Town

An attempt to relax the regulations on the international transfer of tissue samples for conservation research was thwarted last week, when the proposal was referred to a working group of the Convention on International Trade in Endangered Species (CITES).

The decision was made at last week's CITES meeting in Nairobi, Kenya. A proposed amendment was opposed by delegates from the United States, Canada, China, and several African and South American countries. The working group will report at the next CITES congress in two or three years time.

The amendment, sponsored by Switzerland, Germany and the United Kingdom, proposed to exempt DNA, blood, hair, feather and other tissues, apart from live gametes and embryos, from permit requirements when sent to laboratories for diagnostic, identification, research or taxonomic purposes.

It would have freed researchers and CITES administrators from having to obtain and process permits for transferring genetic samples of endangered species, and of nonendangered species that are covered by CITES, such as all primates.

But the amendment's strongest supporters host the world's leading pharmaceutical companies, and this is said to have concerned some delegates. There was also speculation that renewed interest in this old CITES issue had been triggered by demand for blood from the African chimpanzee, following findings that it might have harboured the origin of HIV.

The text of the proposed amendment (document 11.45.1 on the conference agenda) can be viewed at http://www.cites.org/.

Michael Cherry

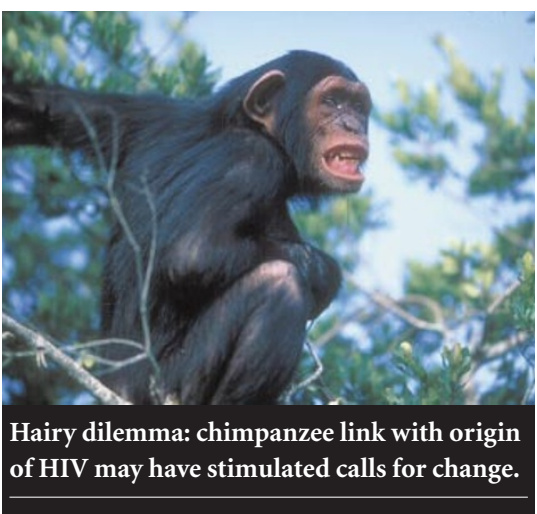

